\title{
Neighboring Plants Alleviate Aluminum Toxicity on The External Hyphae of Gigaspora margarita
}

\author{
AGUS ROHYADI
}

\author{
Faculty of Agriculture, Universitas Mataram, Jalan Majapahit 62, Mataram 83125, Indonesia \\ Phone: +62-370-621435, Fax:+62-370-640189, Email: arohyadi01@telkom.net
}

\begin{abstract}
Excessive soluble aluminum $\left(\mathrm{Al}^{3+}\right)$ in acidic soils is toxic to the external hyphae of arbuscular mycorrhizal fungi but it can be alleviated by other soil factors. A glasshouse experiment was conducted to study the effect of increased $\mathrm{Al}^{3+}$ concentration on the growth of the external hyphae of Gigaspora margarita in the presence of other plants near the host plants. The experiment used compartmentalized pots to facilitate the growth of mycorrhizal-inoculated host plants, external hyphae of the fungus and not mycorhizal-inoculated neighboring plants in different compartments; and measuring the effects of $\mathrm{Al}^{3+}$ and of the neighboring plants on the growth of the fungal hyphae independently. Increased concentration of $\mathrm{Al}^{3+}$ in soil affected the growth of external hyphae of G. margarita negatively. However, the hyphal length density of the fungus was much higher in the pots with neighboring plants than that in the other ones, despite the Al toxicity. This indicates that the hyphae could be taken away from the toxic effect of $\mathrm{Al}^{3+}$ by the stimulating growth from roots of the neighboring plants.
\end{abstract}

Key words: aluminum, cowpea, external hyphae, compartmentalized pot system, Gigaspora margarita

Crops often suffer from adverse conditions of acid soils. Aluminum ( $\mathrm{Al})$ is considered the major stress factor because of its toxicity under acidic conditions. Excessive soluble-Al $\left(\mathrm{Al}^{3+}\right)$ in soil might create a poor plant root system by inhibiting lateral root and root hair formation, and limit the solubility and, therefore, the availability of some essential mineral nutrients, especially P (Baligar et al. 1995). Also, high $\mathrm{Al}^{3+}$ concentration can be detrimental to soil microbes that are involved in nutrient cycling and/or forming symbiotic associations with the plant roots (Wood 1995; Rohyadi 2006). As a result, the plants may have limitation in taking up nutrients and water in sufficient quantity, and consequently they grow stunted.

Arbuscular mycorrhizas (AM) are mutualistic symbioses mostly benefiting plants that have a small and/or coarse root with a lack of root hairs, and those are grown on infertile soils with particularly low available-P. Hence the symbioses can be of great importance in acid soils, where poorly developed root systems and $\mathrm{P}$ deficiency are the main constraints for plant growth (Miyasaka and Habte 2001). However, the AM fungi themselves are subjected to detrimental effects of mainly high $\mathrm{Al}^{3+}$ concentration in acidic soils. Rohyadi (2006) indicated that decreased effectiveness of an AM fungus, Gigaspora margarita on cowpea plant grown on acidic soils was related to the poor growth of the external fungal hyphae because of Al toxicity. It is well known that the external hyphae of AM fungi growing out from colonized plant roots play a crucial role. They develop to form a hyphal net-work in soils and function as an extension of root system to explore soil particularly beyond the depletion of the root zone, take up water and element nutrients there and then transport them to the roots of the host plants (Smith et al. 2000). Therefore, the inhibited growth of the hyphae may directly reduce the symbiotic effectiveness.

Only a few studies were done on the effect of $\mathrm{Al}^{3+}$ on the external hyphae of the AM fungi. It was reported that the growth responses of the AM fungi to Al toxicity are complex and much dependent on the fungal species (Siqueira et al. 1985). Recently, several studies in vitro showed that factors such as $\mathrm{CO}_{2}$ level, some chemical compounds and volatiles released by plant roots, and bacterial products, influence the growth of the fungal hyphae (Tawaraya et al. 1996; Nagahashi and Douds 2000, 2003; Xavier and Germida 2003; Scervino et al. 2005). Therefore, it is believed that the presence of other plants near their hosts will alter the response of the external fungal hyphae to toxic $\mathrm{Al}^{3+}$ in situ.

The objective of this study was to examine if the presence of neighboring plants could modify the growth response of the external hyphae of G. margarita to the detrimental effects of $\mathrm{Al}^{3+}$.

\section{MATERIALS AND METHODS}

The fungus used in this study was G. margarita Becker $\&$ Hall (BEG collection), which is tolerant to and working effectively under acidic soil conditions (Rohyadi et al. 2004). The fungus was propagated in pot cultures of Trifolium subterranean $\mathrm{L}$. in a sand and soil $(90: 10, \mathrm{w} / \mathrm{w})$ mixture for 4 months. Another pot without the fungus to provide mycorrhiza-free inoculums was included. The cultivar of cowpea used was Red Caloona supplied by CSIRO Tropical Agriculture, Brisbane, Australia. The growth medium was a mixture of sand and acidic podsolic soil of grey sandy loam $(90: 10, w / w)$. The mixture was firstly fertilized with (in $\mathrm{mg} \mathrm{kg}$ ${ }^{1}$ medium) $59.4 \mathrm{NH}_{4}-\mathrm{N}, 178.2 \mathrm{NO}_{3}-\mathrm{N}, 36 \mathrm{P}, 54 \mathrm{~S}, 214.2 \mathrm{~K}, 18.9$ $\mathrm{Mg}, 114.3 \mathrm{Ca}, 13.5 \mathrm{Na}, 8.1 \mathrm{Cl}, 2.7 \mathrm{Fe}, 0.45 \mathrm{~B}, 0.45 \mathrm{Mn}, 0.225 \mathrm{Zn}$, $0.036 \mathrm{Cu}$ and $0.009 \mathrm{Mo}$. Then it was treated with $0,75,150$ or $300 \mathrm{Al}_{2}\left(\mathrm{SO}_{4}\right)_{3}$. The concentrations of $\mathrm{Al}^{3+}$ (measured based on the method of Close and Powell 1989) in the final established media $\left(\mathrm{A}_{0}, \mathrm{~A}_{1}, \mathrm{~A}_{2}\right.$ or $\mathrm{A}_{3}$ ) were $0.4,1.1,4.1$ or $7.3 \mathrm{mg}$ $\mathrm{kg}^{-1}$ soil respectively.

This experiment was conducted under glasshouse conditions. It was a $2 \times 3 \times 2$ factorial experiment consisting of two levels of mycorrhiza with $\left(\mathrm{M}_{1}\right)$ and without (Mo) inoculation. Three concentrations of $\mathrm{Al}^{3+}$ established in soil were 1.1, 4.1 and $7.3 \mathrm{mg} \mathrm{kg}^{-1}$ soil (denoted as $\mathrm{A}_{1}, \mathrm{~A}_{2}$ and $\mathrm{A}_{3}$ ), and the presence and absence of neighboring plants were denoted as $\mathrm{N}_{1}$ and $\mathrm{N}_{0}$ respectively. There were six replicates per treatment combination. 
The pot system used was made of a PVC pipe (Fig 1), divided into three compartments by two vertical $30 \mu \mathrm{m}$ screen meshes that allow hyphae to pass but exclude plant roots. The first compartment, the host plant compartment (HPC), was for plants inoculated or not inoculated with mycorrhiza fungal structures, designated as the host plants. They supplied the external fungal hyphae being tested. The second compartment in the middle of the pot, the external hyphal compartment (EHC), was a root free compartment provided for the external hyphae extending from mycorrhizal-colonized roots of the host plants in the HPC. The third compartment, the neighboring plant compartment (NPC), was for noninoculated plants, denoted as neighboring plants, which acted as a growth promoter for the fungal hyphae to traverse the EHC. In order to provide favorable conditions for plant roots, the HPC and NPC were filled with growth medium not treated with $\mathrm{Al}, \mathrm{A}_{0}\left(\mathrm{pH} \mathrm{5.3}\right.$, containing $0.4 \mathrm{mg} \mathrm{Al}^{3+} \mathrm{kg}^{-1}$ soil and 26 ppm Bray-1 P), whereas the medium in EHC was treated with $\mathrm{Al}$ at different concentrations. Therefore, the basic purpose of using the compartmentalized pot system is to allow the external fungal hyphae from mycorrhizal-colonized roots of the host plants in the HPC to extend into the EHC, interact with $\mathrm{Al}$ and possibly traverse to the NPC, and finally colonize roots of neighboring plants there. The effects of the $\mathrm{Al}^{3+}$ concentrations in the EHC and the presence of neighboring plants in the NPC on the growth of the external hyphae was determined by the extending of the external hyphae in the EHC and the colonization of neighboring plants in the NPC by the AM fungus.

At the beginning of the experiment, HPC and NPC were filled with $320 \mathrm{~g}$ of $\mathrm{A}_{0}$ soil, but only the HPC was inoculated with $10 \%$ (w/w) of pot culture inoculums of G. margarita or was left not-inoculated to provide mycorrhizal and nonmycorrhizal colonized host plants. Two pre-germinated seeds of cowpea (cv. Red Caloona) were transplanted into all of the HPC and a half of the NPC, and then left grown for two weeks. The EHC was then filled with $260 \mathrm{~g}$ of $\mathrm{A}_{1}, \mathrm{~A}_{2}$ or $\mathrm{A}_{3}$ soils in the

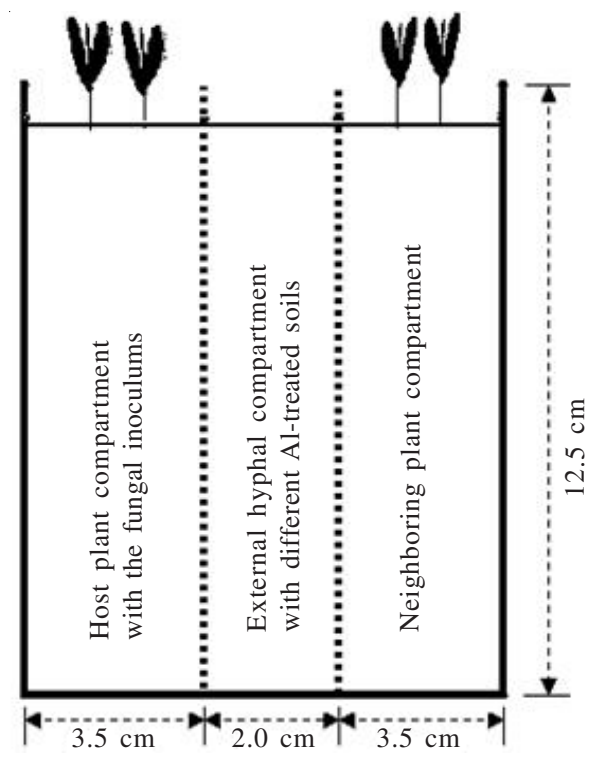

Fig 1 Schematic representation of the compartmentalized pot system. The compartments are separated by two vertical $30 \mu \mathrm{m}$ nylon screen meshes ( - - - ) that can be crossed by fungal hyphae but not by plant roots. same way. Reverse Osmotic (RO) water, adjusted to $\mathrm{pH} 4.6$ with $\mathrm{H}_{2} \mathrm{SO}_{4}$, was used on a weight loss basis to maintain the moisture content of the growth media at the field capacity (about $0.1 \mathrm{~g} \mathrm{~g}^{-1}$ soil) and the $\mathrm{pH}$ of soil in the EHC, at about 4.7 throughout the experiment.

Plants were harvested 6 and 10 weeks $\left(\mathrm{H}_{1}\right.$ and $\left.\mathrm{H}_{2}\right)$ after transplanting. The dry biomass and root length of the host plants, the dry biomass of the neighboring plants, the mycorrhizal colonization on the roots of these plants, and the length density of the external fungal hyphae in the EHC were measured. Plant biomass was weighed after it was dried at $70{ }^{\circ} \mathrm{C}$ for 48 hours. To measure root length and percentage of mycorrhizal colonization, root samples were cleared with $10 \% \mathrm{KOH}$, and stained with trypan blue in lacto-glycerol and then assessed under a dissecting microscope using a gridline intersect method (Giovannetti and Mosse 1980). To measure length density of the external fungal hyphae in the HPC, representative samples of the growth media were taken from the compartment. The hyphae in the soil samples were then extracted following the aqueous membrane-filtration method of Jakobsen et al. (1992), and assessed under microscopic observation (see detail in Rohyadi 2006).

The data were statistically analyzed using ANOVA after grouping them into plant compartments and harvest times. The LSD tests at $\mathrm{p} \leq 0.05$ were then applied to determine the significant differences among ways of treatment.

\section{RESULTS}

Growth of Host Plant. Dry biomass of the host plants, measured at any harvest was not affected by the $\mathrm{Al}^{3+}$ concentration in the EHC or by the presence $\left(\mathrm{N}_{1}\right)$ and the absence $\left(\mathrm{N}_{0}\right)$ of neighboring plants in the NPC, but was significantly affected by mycorrhizal inoculation. The dry biomass of mycorrhizal $\left(\mathrm{M}_{1}\right)$-plants was significantly higher than that of non-mycorrhiza $\left(\mathrm{M}_{0}\right)$ (Table 1). Similarly, mycorrhizal inoculation significantly increased the root length of the host plants in the HPC regardless of the presence or absence of neighboring plants. Aluminum concentration and the presence of neighboring plants had no significant effect on the growth of roots irrespective of the mycorrhizal status of plants.

Mycorrhizal Colonization on Host Plants. Plants not inoculated with AM fungus exhibited no evidence of AM fungal colonization, while the extent of roots colonized by AM fungus and the root length of host plants were stimulated by inoculation (Table 1). In general, mycorrhizal colonization increased from the first to the second harvest. However, the increases were not related to the $\mathrm{Al}^{3+}$ concentration in the EHC. The presence of neighboring plants reduced mycorrhizal colonization observed in the HPC at the second but not at the first harvest.

The effect of $\mathrm{Al}^{3+}$ concentration and neighboring plants on the length of the mycorrhizal colonized roots in the HPC was nil at the first harvest. At the second harvest, the adverse effect of $\mathrm{Al}^{3+}$ on the mycorrhizal-colonized root length was dependent on the presence or absence of neighboring plants. It was found that the presence of neighboring plants was more detrimental than that the adverse effect of $\mathrm{Al}^{3+}$ on the root colonization by the fungus. 
Table 1 Growth and AM fungal colonization on roots of host plants in the HPC in response to mycorrhizal inoculation, $\mathrm{Al}^{3+}$ concentration in the EHC and the presence of neighboring plants in the NPC

\begin{tabular}{|c|c|c|c|c|c|c|c|c|c|c|}
\hline \multirow[b]{2}{*}{$\begin{array}{l}\text { Mycorrhizal } \\
\text { inoculation } \\
\text { in the HPC }\end{array}$} & \multicolumn{2}{|l|}{ Treatments } & \multicolumn{2}{|c|}{$\begin{array}{c}\text { Plant dry } \\
\text { biomass (mg) }\end{array}$} & \multicolumn{2}{|c|}{ Root length $(\mathrm{cm})$} & \multicolumn{2}{|c|}{$\begin{array}{c}\text { Root } \\
\text { colonization } \\
(\%)\end{array}$} & \multicolumn{2}{|c|}{$\begin{array}{c}\text { Mycorrhizal } \\
\text { root length }(\mathrm{cm})\end{array}$} \\
\hline & $\begin{array}{l}\mathrm{mg} \mathrm{Al}^{3+} \mathrm{kg}^{-1} \text { soil } \\
\text { in the } \mathrm{EHC}\end{array}$ & $\begin{array}{l}\text { Neighboring plants } \\
\text { in the NPC }\end{array}$ & $\mathrm{H}_{1}$ & $\mathrm{H}_{2}$ & $\mathrm{H}_{1}$ & $\mathrm{H}_{2}$ & $\mathrm{H}_{1}$ & $\mathrm{H}_{2}$ & $\mathrm{H}_{1}$ & $\mathrm{H}_{2}$ \\
\hline \multirow{6}{*}{$\begin{array}{c}\text { Not } \\
\text { inoculated }\end{array}$} & 1.1 & $\mathrm{~N}_{0}$ & $245^{a}$ & $441^{\mathrm{b}}$ & $627^{b}$ & $1202^{\mathrm{b}}$ & 0 & 0 & 0 & 0 \\
\hline & & $\mathrm{N}_{1}^{0}$ & $272^{a}$ & $460^{\mathrm{b}}$ & $706^{\mathrm{ab}}$ & $1107^{\mathrm{b}}$ & 0 & 0 & 0 & 0 \\
\hline & 4.1 & $\mathrm{~N}_{0}^{1}$ & $260^{\mathrm{a}}$ & $411^{\mathrm{b}}$ & $682^{\mathrm{b}}$ & $1072^{\mathrm{b}}$ & 0 & 0 & 0 & 0 \\
\hline & & $\mathrm{N}_{1}^{0}$ & $248^{a}$ & $419^{b}$ & $647^{b}$ & $1049^{\mathrm{b}}$ & 0 & 0 & 0 & 0 \\
\hline & 7.3 & $\mathrm{~N}_{0}$ & $249^{a}$ & $361^{\mathrm{b}}$ & $657^{\mathrm{b}}$ & $1026^{\mathrm{b}}$ & 0 & 0 & 0 & 0 \\
\hline & & $\mathrm{N}_{1}^{0}$ & $235^{\mathrm{a}}$ & $392^{\mathrm{b}}$ & $639^{\mathrm{b}}$ & $1035^{\mathrm{b}}$ & 0 & 0 & 0 & 0 \\
\hline \multirow[t]{6}{*}{ Inoculated } & 1.1 & $\mathrm{~N}_{0}$ & $311^{\mathrm{a}}$ & $829^{a}$ & $876^{\mathrm{a}}$ & $1420^{\mathrm{a}}$ & $42^{\mathrm{a}}$ & $77^{\mathrm{a}}$ & $368^{\mathrm{ab}}$ & $1093^{\mathrm{a}}$ \\
\hline & & $\mathrm{N}_{1}^{0}$ & $327^{a}$ & $815^{a}$ & $849^{a}$ & $1488^{\mathrm{a}}$ & $46^{\mathrm{a}}$ & $57^{\mathrm{b}}$ & $391^{\mathrm{ab}}$ & $848^{b}$ \\
\hline & 4.1 & $\mathrm{~N}_{0}^{1}$ & $341^{\mathrm{a}}$ & $792^{\mathrm{a}}$ & $872^{\mathrm{a}}$ & $1535^{\mathrm{a}}$ & $50^{\mathrm{a}}$ & $76^{\mathrm{a}}$ & $436^{\mathrm{a}}$ & $1167^{\mathrm{a}}$ \\
\hline & & $\mathrm{N}_{1}^{0}$ & $345^{a}$ & $814^{\mathrm{a}}$ & $829^{a}$ & $1483^{\mathrm{a}}$ & $42^{\mathrm{a}}$ & $56^{\mathrm{b}}$ & $349^{b}$ & $830^{\mathrm{b}}$ \\
\hline & 7.3 & $\mathrm{~N}_{0}$ & $361^{\mathrm{a}}$ & $797^{\mathrm{a}}$ & $882^{\mathrm{a}}$ & $1496^{\mathrm{a}}$ & $48^{\mathrm{a}}$ & $73^{\mathrm{a}}$ & $423^{\mathrm{a}}$ & $1092^{\mathrm{a}}$ \\
\hline & & $\mathrm{N}_{1}^{0}$ & $325^{\mathrm{a}}$ & $745^{\mathrm{a}}$ & $791^{\mathrm{a}}$ & $1458^{a}$ & $42^{\mathrm{a}}$ & $51^{\mathrm{b}}$ & $332^{\mathrm{b}}$ & $744^{\mathrm{c}}$ \\
\hline
\end{tabular}

${ }^{a}$ Means within a selected column followed by different superscripts are significantly different based on the LSD-test at $\mathrm{p} \leq 0.05$. HPC: host plant compartment; EHC: external hyphal compartment; NPC: neighboring plant compartment. $\mathrm{H}_{1}$ and $\mathrm{H}_{2}$ : harvest at 6 and 10 weeks after transplanting.

Growth of External Hyphae. The growth of external fungal hyphae in the EHC increased with harvest times; the extent was dependent on the $\mathrm{Al}^{3+}$ concentration and the presence of neighboring plants in the NPC. However, there was no a significant interaction between the two factors. The hyphal length density (HLD) decreased with increased $\mathrm{Al}^{3+}$ concentration, but the adverse effect of $\mathrm{Al}^{3+}$ was nullified by the presence of neighboring plants (Fig 2).

\section{Mycorrhizal Colonization and Growth of Neighboring}

Plant. Table 2 clearly shows the fungal hyphae, which traverse the EHC, were able to definitely colonize roots of plants in the NPC. At $\mathrm{H}_{1}$, the colonization was less than $20 \%$, but increased to more than $40 \%$ at $\mathrm{H}_{2}$. It also shows that different $\mathrm{Al}^{3+}$ concentrations in the $\mathrm{EHC}$ affect the colonization rates differently. At $\mathrm{H}_{1}$ compared to the root colonization in pots with $\mathrm{A}_{1}$, a significant reduction in the percentage of colonized roots only occurred in pots with $\mathrm{A}_{3}$; meanwhile, at $\mathrm{H}_{2}$ such reduction was already evident in pot with $\mathrm{A}_{2}$. In general, the growth of the neighboring plants increased, but was not related to soluble-Al concentration in the EHC. Differences in plant growth occurred between plants in pots inoculated with $\left(\mathrm{M}_{1}\right)$ and without mycorrhiza $\left(\mathrm{M}_{0}\right)$. The dry biomass of the neighboring $\mathrm{M}_{1}$-plants was higher than that of the

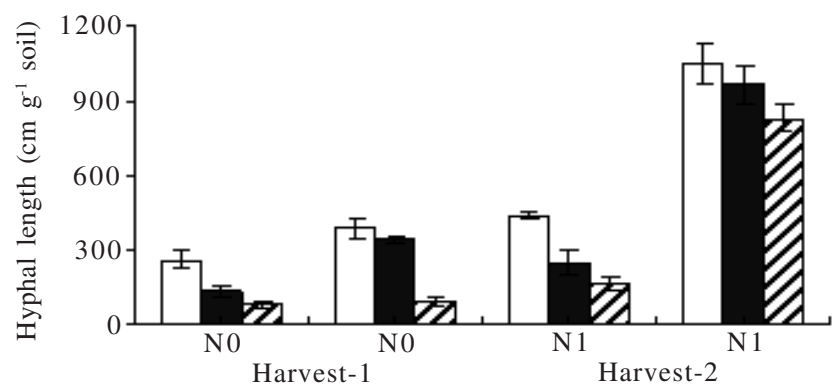

Fig 2 The influence of $\mathrm{Al}^{3+}$ concentrations and neighboring plants on hyphal length density of Gigaspora margarita in the external hyphal compartment (Bars represent means \pm sem, $n=3$ ); $\square, A_{1} ; \mathbf{\square}, A_{2}$, and $\square, \mathrm{A}_{3}$ are growth media with 1.1, 4.1 and $7.3 \mathrm{mg} \mathrm{Al}{ }^{3+} \mathrm{kg}^{-1}$ soil; $\mathrm{N}_{1}$ and $\mathrm{N}_{0}$ are pots with and with no neighboring plants.
Table 2 Dry biomass and root colonization of the neighboring plants relating to mycorrhizal inoculation in the $\mathrm{HPC}$ and $\mathrm{Al}^{3+}$ concentrations in the EHC observed at two harvest times

\begin{tabular}{|c|c|c|c|c|c|}
\hline \multicolumn{2}{|l|}{ Treatments } & \multicolumn{2}{|c|}{$\begin{array}{c}\text { Plant dry } \\
\text { biomass }(\mathrm{mg})\end{array}$} & \multicolumn{2}{|c|}{$\begin{array}{c}\text { Root } \\
\text { Colonization } \\
(\%) \\
\end{array}$} \\
\hline $\begin{array}{l}\text { Mycorrhizal } \\
\text { inoculation } \\
\text { in the HPC }\end{array}$ & $\begin{array}{c}\mathrm{mg} \mathrm{Al}^{3+} \mathrm{kg}^{-1} \text { soil } \\
\text { in the } \mathrm{EHC}\end{array}$ & $\mathrm{H}_{1}$ & $\mathrm{H}_{2}$ & $\mathrm{H}_{1}$ & $\mathrm{H}_{2}$ \\
\hline \multirow{3}{*}{ Not inoculated } & 1.1 & $210^{\mathrm{a}}$ & $382^{\mathrm{b}}$ & 0 & 0 \\
\hline & 4.1 & $210^{\mathrm{a}}$ & $399^{\mathrm{b}}$ & 0 & 0 \\
\hline & 7.3 & $195^{\mathrm{a}}$ & $397^{b}$ & 0 & 0 \\
\hline \multirow[t]{3}{*}{ Inoculated } & 1.1 & $255^{\mathrm{a}}$ & $509^{a}$ & $18^{\mathrm{a}}$ & $59^{a}$ \\
\hline & 4.1 & $247^{\mathrm{a}}$ & $532^{\mathrm{a}}$ & $17^{\mathrm{a}}$ & $48^{\mathrm{b}}$ \\
\hline & 7.3 & $242^{\mathrm{a}}$ & $589^{a}$ & $8^{\mathrm{b}}$ & $39^{\mathrm{bc}}$ \\
\hline
\end{tabular}

a Means within a selected column followed by different superscripts are significantly different based on the LSD-test at $\mathrm{p} \leq 0.05$; HPC: host plant compartment; EHC: external hyphal compartment; $\mathrm{H}_{1}$ and $\mathrm{H}_{2}$ : harvest at 6 and 10 weeks after transplanting.

neighboring $\mathrm{M}_{0}$-plants regardless of the $\mathrm{Al}^{3+}$ concentration in the EHC, even though it was only significant at $\mathrm{H}_{2}$ (Table 2).

\section{DISCUSSION}

The results of this study showed that the toxicity of high $\mathrm{Al}^{3+}$ concentrations in soil solution to the external hyphae of G. margarita was evident. The growth of the hyphae was depressed particularly when neighboring plants were absent. This supports and extends previous results of work in vitro indicating the inhibitory effects of $\mathrm{Al}^{3+}$ on spore germination, germ tube elongation (Siqueira et al. 1985), and root colonization of the fungus (Rohyadi 2005). On the other hand, in pots with neighboring plants the growth of the external fungal hyphae considerably increased (Fig 2), which corresponds with the decrease in percentage of the mycorrhizal colonization on roots of their host plants (Table 1). This suggests the importance of the presence of neighboring plants for the growth of external hyphae of the fungus. Previously, Mummey et al. (2005) showed the 
significance of neighboring plants on the diversity and community composition of the AM fungi in the field.

Most studies on the interaction of AM fungi and plant roots have been carried out using in vitro systems. The significant effects of the presence of plant roots on hyphal growth have been demonstrated. Sbrana and Giovannetti (2005) showed a chemotropism in elongation of germ tube of Glomus mossea in response to the presence of plant roots. It seems that the plant roots produced influential stimuli for the growth of the AM fungal hyphae. Root exudates, in this case, play a key role during the pre-symbiotic phase. For instance, it was reported that hyphal growth of G. margarita was stimulated by root exudates of onion (Tawaraya et al. 1996) and tomato (Scervino et al. 2005). Also, a component of root exudates of Lotus japonicum, identified as strigolactone, induced an extensive branching of the fungal hyphae at very low concentration (Akiyama et al. 2005). In general, some phenolic and flavonoid compounds, and/or volatile metabolite exuded by roots of mycotrophic plants have been recognized as chemical stimuli for hyphal elongation and branching (Nagahashi and Douds 2003; Akiyama et al 2005), or as a chemical signal leading the hyphae to grow forward (Vierheilig et al. 1998; Steinkellner et al. 2007). Therefore, in the present study in situ it was possible that some eliciting factors produced by roots of the neighboring plants have triggered most of the external hyphae of the fungus to grow out of the HPC, and so it left a small number of the fungal inoculums to initiate new root colonization in the plant compartment.

Moreover, in this study it was found that colonization of the roots of neighboring plants by the fungal hyphae traversing the EHC reached about $40 \%$ (Table 2), suggesting that exposure to increasing $\mathrm{Al}^{3+}$ concentrations did not really affect the function of the external hyphae of G. margarita as inoculums. The growing hyphae remained viable to initiate new colonization. This is very important for field practice since spores begin most colonization by this fungus. Other results on the increased growth of neighboring plants (Table 2) also indicate that the fungal hyphae did not suffer from the loss of their ability to improve the growth of cowpea plant after being exposed to high concentrations of $\mathrm{Al}^{3+}$, even though there was a delay in seeing a significant contribution to the plants.

To summarize, the results of this study have broadened our understanding on eco-physiological aspects of AM symbiosis in acid soils particularly with problems of $\mathrm{Al}$ toxicity. It is clear that increasing concentrations of solubleAl might directly reduce the growth rate of the external hyphae of G. margarita in soil, but functions of the hyphae as inoculums and as an extension of the plant root system were not really affected. Meanwhile, the presence of the roots of neighboring plants stimulated the external hyphae to grow further, irrespective of the toxic $\mathrm{Al}^{3+}$ in soil. These results, in general, suggest that plants need more AM symbioses to grow better particularly under adverse soil conditions, which is comparable to the requirement of the AM fungi themselves to get carbon from the plants. Therefore, from this point of view, developing a suitable cropping system is essential for empowering AM fungi to be persistent and be able to continually develop their external hyphae. Further studies however are needed to investigate deep mechanisms and other soil factors involved in triggering the growth of the fungal hyphae under regimes of different mycotrophic crop species, and of adverse soil conditions.

\section{ACKNOWLEDGEMENTS}

I wish thank Sally S Smith, F Andrew Smith, and Rob S Murray (The University of Adelaide, Waite Campus, The South Australia) for their help in many ways thoughout this work. I also thank AusAID Scholarship, Australia for the financial support.

\section{REFERENCES}

Akiyama K, Matsuzaki K, Hayashi H. 2005. Plant sesquiterpenes induce hyphal branching in arbuscular mycorrhizal fungi. Nature 435:824-7.

Baligar VC, Anghinoni L, Pitta GVE, dos Santos HL, Filho EC, Schaffert RE. 1995. Aluminium effects on plant and nutrient uptake parameters of soil and solution grown sorghum genotypes. J Plant Nut 18:2325-38.

Close EA, Powell HKJ. 1989. Rapidly extracted (0.02 $\mathrm{M} \mathrm{CaCl}_{2}$-soluble) 'reactive' aluminium as a measure of aluminium toxicity in soils. Aust J Soil Res 27:663-72.

Giovannetti M, Mosse B. 1980. An evaluation of techniques for measuring vesicular-arbuscular mycorrhizal infection in roots. New Phytol 84:489-500.

Jakobsen I, Abbott LK, Robson AD, 1992. External hyphae of vesiculararbuscular mycorrhizal fungi associated with Trifolium subterranean L. 1. Spread of hyphae and phosphorus inflow into roots. New Pythol 120:371-80

Miyasaka SC, Habte M. 2001. Plant mechanisms and mycorrhizal symbioses to increase phosphorus uptake efficiency. Commun Soil Sci Plant Anal 32:1101-47.

Mummey DL. Rillig MC, Holben WE. 2005. Neighboring plant influences on arbuscular mycorrhizal fungal community composition as assessed by T-RFLP analysis. Plant Soil 271:8390 .

Nagahashi G, Douds DD. 2000. Partial separation of root exudate components and their effects upon the growth of germinated spores of AM fungi. Mycol Res 104:1453-64.

Nagahashi G, Douds DD. 2003. Action spectrum for the induction of hyphal branches of an arbuscular mycorrhizal fungus: exposure sites and branching sites. Mycol Res 107:1075-82.

Rohyadi A. 2005. Spore germination and colonization of Gigaspora margarita as influenced by aluminium concentration. J Mikrobiol Indones 10:71-4.

Rohyadi A. 2006. Elevated aluminium concentrations in soil reduce growth and function of external hyphae of Gigaspora margarita in growth of cowpea plants. Bionatura 8:47-59.

Rohyadi A, Smith FA, Murray RS, Smith SE. 2004. Effect of pH on mycorrhizal colonisation and nutrient uptake in cowpea under conditions that minimise confounding effects of elevated available aluminium. Plant Soil 260:283-90.

Sbrana CM, Giovannetti M. 2005. Chemotropism in the arbuscular mycorrhizal fungus Glomus mosseae. Mycorrhiza 15:539-45.

Scervino JM, Ponce MA, Erra-Bassels R, Vierheilig H, Ocampo JA, Godeas A. 2005. Arbuscular mycorrhizal colonization of tomato by Gigaspora and Glomus species in presence of roots flavonoids. J Plant Physiol 162:625-33.

Siqueira JO, Sylvia DM, Gibson J, Hubbell DH. 1985. Spores, germination, and germ tubes of vesicular-arbuscular mycorrhizal fungi. Can J Microbiol 31:965-71.

Smith FA, Jakobsen I, Smith SE. 2000. Spatial differences in acquisition of soil phosphate between two arbuscular mycorrhizal fungi in symbiosis with Medicago truncatula. New Phytol 147:357-66.

Steinkellner S, Lendzemo V, Langer I, Schweiger P, Khaosaad T, Toussaint JP, Vierheilig H. 2007. Flavonoids and strigolactones in root exudates as signals in symbiotic and pathogenic plant-fungus interactions. Molecules 12:1290-306. 
Tawaraya K, Watanabe S, Yoshida E, Wagatsuma T. 1996. Effect of onion (Allium cepa) root exudates on the hyphal growth of Gigaspora margarita. Mycorrhiza 6:57-9.

Vierheilig H, Alt-Hug M, Engel-Streitwolf R, Mäder P, Wiemken A. 1998. Studies on the attractional effect of root exudates on hyphal growth of an arbuscular mycorrhizal fungus in a soil compartmentmembrane system. Plant Soil 203:137-44.
Wood M. 1995. A mechanism of aluminium toxicity to soil bacteria and possible ecological implications. Plant Soil 171:63-9.

Xavier LJC, Germida JJ. 2003. Bacteria associated with Glomus clarum spores influence mycorrhizal activity. Soil Biol Biochem $35: 471-8$. 